\title{
智能船舶工程科技发展战略研究
}

\author{
郎舒妍 ${ }^{1}$, 曾晓光 ${ }^{1}$, 张民 $^{2}$ \\ （1. 中国船舶重工集团公司第七一四研究所，北京 100101；2. 中国船舶重工国际贸易有限公司，北京 100861）
}

摘要：随着新兴技术的快速发展, 智能船舶逐渐成为船舶工业发展热点。本文介绍了智能船舶技术分类, 梳理现阶段国内外 智能船舶技术发展现状, 研究国外智能船舶技术发展特点, 分析我国智能船舶技术发展存在的问题, 建议我国在智能船舶技 术发展中采取研发与应用并重, 分步实施的发展模式, 同时加大产学研合作力度, 建立船岸一体综合服务模式, 并进一步加 强人才队伍建设。

关键词：船舶智能化；智能船舶技术；智能船舶

中图分类号: S931

文献标识码: A

\section{Development Strategy of Intelligent Ship Engineering Technology}

\section{Lang Shuyan ${ }^{1}$, Zeng Xiaoguang ${ }^{1}$, Zhang Min ${ }^{2}$}

(1. Shipbuilding Information Center of China, Beijing 100101, China; 2. China Shipbuilding \& Offshore International Co., Ltd., Beijing 100861, China)

\begin{abstract}
With the rapid development of emerging technologies, intelligent ship has gradually become a hot spot for development in the shipbuilding industry. In this study, we introduced the technical classification of intelligent ships, summarized the current development status of intelligent ship technology in China and abroad, studied the characteristics of its development abroad, and analyzed the existing problems in its development in China. Furthermore, we suggest that China should pay equal attention to R \& D and application of the intelligent ship technology, promote its development step by step, strengthen cooperation among the industry, university, and research institute, establish a comprehensive service mode with ship-shore integration, and further strengthen the construction of talent teams.
\end{abstract}

Keywords: ship intelligentization; intelligent ship technology; intelligent ship

近年来，随着新兴技术的快速发展。“智能化” 逐步走进人们的视野, “汽车智能化” “医疗智能化”, 甚至 “城市智能化”，诸如此类概念的提出和应用，
正在极大地改变着人们的生活。作为传统行业的船 舶工业，在外部技术推动与内生需求牵引的双重作 用下，也在加快发展船舶智能化技术，开发智能船

收稿日期 : 2019-10-12; 修回日期 : 2019-10-19

通讯作者：郎舒妍，中国船舶重工集团公司第七一四研究所工程师，研究方向为海洋装备技术; E-mail: csic_lsy@163.com 资助项目：中国工程院咨询项目 “海洋强国战略研究 2035” (2018-ZD-08); 中国工程院咨询项目 “面向 2035 年的智能海洋运载装备工程科 技发展战略研究” (2017-ZCQ-1)

本刊网址：www.engineering.org.cn/ch/journal/sscae 
舶, 推动行业发展迈向新阶段。

\section{一、智能船舶技术分类}

智能化是指利用先进的数据传输技术、“互联 网 + ” 技术、人工智能技术以及数控技术等联合在 一起对某个对象展开应用, 这些应用主要包括自 主学习、故障诊断、自主评价、态势感知以及行 为决策等 [1]。智能化一般具有以下 4 个方面的特 点: 一是具备感应外部信息的能力, 即能够收集、 整理来自外部环境的信息; 二是具有自主分析能 力, 通过感应获得的外部信息, 利用已经存在的程 序设定和知识储备对感应的外部信息进行分析、比 较、计算、预测等; 三是具备自主学习能力, 能够 通过对以往案例的数据信息进行分析研究, 并以此 反复学习新环境变化带来的知识; 四是具备自主决 策能力, 可对外部环境的变化进行分析研究, 形成 并传输相应的对策信息。

船舶智能化不仅仅表现在船体本身，新技术的 兴起将会深入到船舶设计、建造、营运各个阶段, 简化船舶设计建造流程, 优化船舶各项功能, 提高 效率, 提升经济性 [2]。智能船舶技术分类, 如表 1 所示。

\section{二、智能船舶技术的发展现状}

\section{（一）国外智能船舶技术的发展现状}

在智能船舶装备方面, 新兴技术的崛起, 如云 计算技术、卫星通信技术、传感器技术等, 带动船 舶工业走向数字化、网络化和智能化。可以说, 智 能船舶为船舶安全、节能、环保、高效等技术需求 带来了发展的新契机, 为航运业实现降本增效、低 碳经济带来了新希望, 智能船舶为船舶工业技术发 展提供了新的动力和方向 [3]。当前, 在世界范围 内, 美国、日本、韩国、欧洲都在积极发展智能船 舶装备技术, 发展路径大多一致, 但各有侧重。

自 2010 年起, 韩国现代重工集团先后启动了 “智能船舶 1.0/2.0” 计划, 项目研究内容旨在研发 基于有/无线船舶综合管理网通信技术的船舶主机 远程监控系统, 以此实现经济、安全、高效航行服 务。2011 年, 韩国三星重工集团开发了船舶能效 管理系统, 该能效管理系统能够收集并整理船舶在
表 1 智能船舶技术分类

\begin{tabular}{lc}
\hline 技术集群 & 技术分类 \\
\hline 智能装备 & 能效管理 \\
& 货物管理 \\
& 态势感知 \\
& 通信导航 \\
& 航行规划 \\
& 状态监测与故障诊断 \\
智能设计 & 自主航行 \\
& 专家系统辅助设计 \\
& 机器学习与辅助决策 \\
智能制造 & 深度学习与人工智能设计 \\
& 智能车间 \\
智能航运 & 智能工厂 \\
& 船舶交通管理 \\
& 航运物流服务系统 \\
& 智能港口 \\
\hline
\end{tabular}

运营过程中机舱内的数据信息, 通过通信技术、数 据分析技术、决策支持技术, 提高船舶能效管理智 能化水平。此外, 2012 年 12 月, 由日本船舶配套 协会和日本船技术等多家企业和科研院所着手开展 “智能船舶应用平台” 项目研究。“智能船舶应用平 台” 主要是通过研发智能信息与控制系统, 使得船 舶实现机舱状态监测、船体外部环境感知、远程运 维等功能 (见图 1)。2016 年, 罗尔斯罗伊斯公司 推出了 “高级无人驾驶船舶应用开发计划” (AAWA) 白皮书, 白皮书中预计到 2020 年, 利用远程操作 和辅助功能操作来实现船舶少人化; 到 2025 年实 现近海船舶的远程遥控; 到 2030 年实现远洋无人 船舶的远程控制; 到 2035 年实现自主远洋无人船 舶 (见图 2)。

在智能设计方面, 当前美国、日本、韩国、欧 洲国家等在船舶智能化设计中占据领先水平, 并已 普遍采用三维设计建模, 实现了设计和生产协同一 体化。2009年, 美国电船公司以每年建造两艘 “弗 吉尼亚级” 潜艇和每艘成本降至 20 亿美元为目标, 完成了 “面向制造的设计” 项目研究。同年, 美国在 CVN-78 设计中以计算机辅助三维交互应用 (CATIA) 为核心, 在应用洞穴状自动虚拟系统 (CAVE) 技术 的基础上, 实施被称为三维可视化协同工具 (ROVR) 的新一代沉浸式三维虚拟现实系统, 实现基于 CATIA 三维设计模型的浏览、漫游与协同。 
船舶

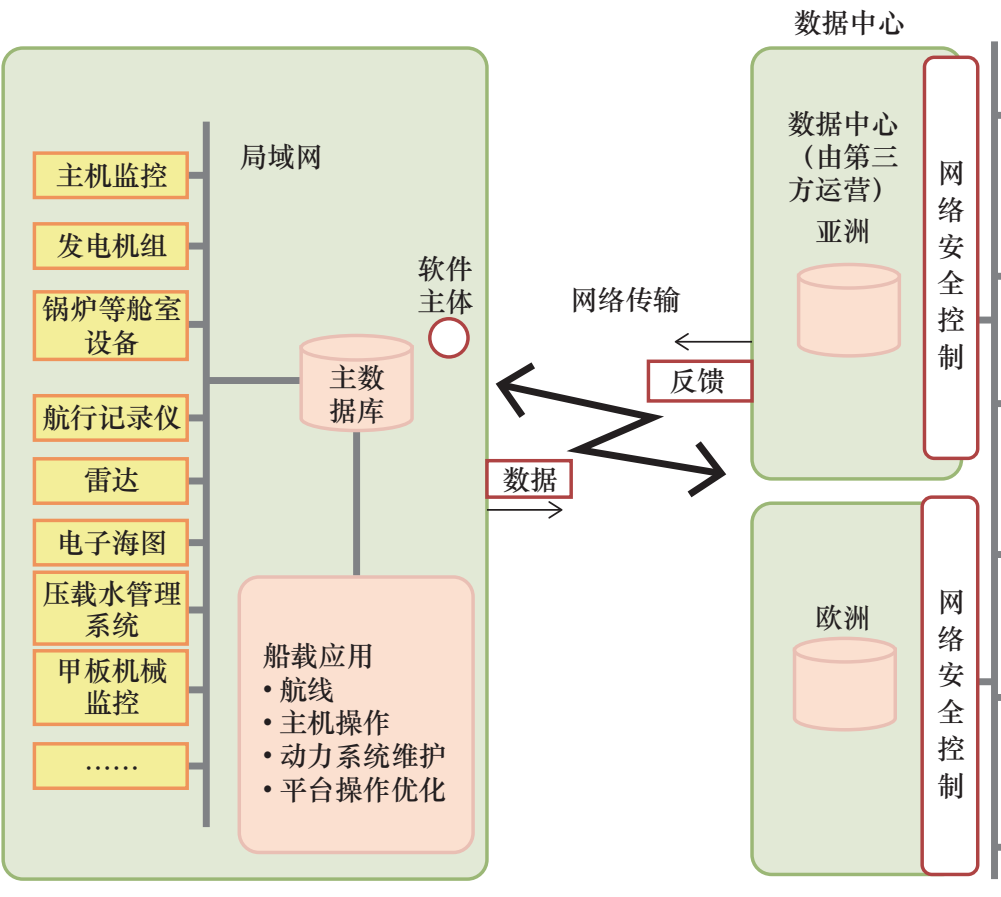

岸基中心

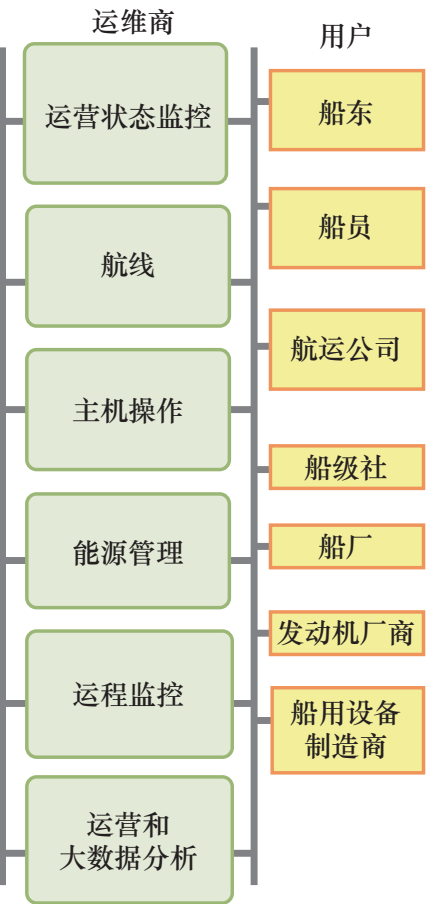

图 1 智能船舶应用平台系统结构图

路线图

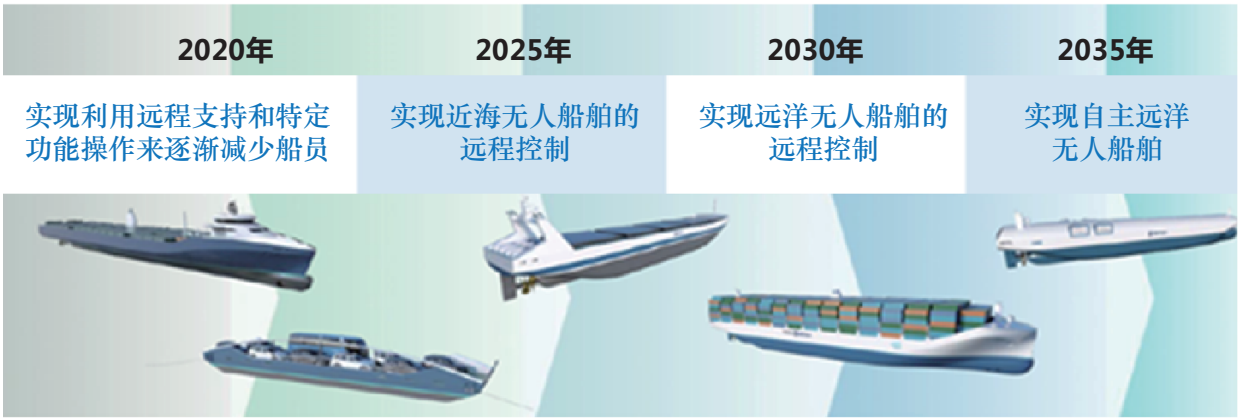

图 2 罗尔斯罗伊斯公司无人船舶技术路线图

在智能制造方面，世界各大船企都在积极布局 “智能化”制造模式，希望利用丰富的数据来提高 设计和建造的效率。为振兴造船海洋事业, 韩国政 府积极推进智能船厂建设, 先后提出一系列重点研 发计划。日本政府也提出 “i-shipping” 概念, 旨在 利用数字化技术、互联网及大数据等技术打造可视 化船厂。2016 年, 大宇造船海洋工程有限公司提出 “shipyard 4.0” 概念, 意在搭建物联网平台, 将 3D 设计生产信息系统向移动端延伸, 助力配套企业构 建智能工厂。2017 年, 韩国现代重工集团提出建设 “smart factory”, 内容主要包括构建智能工作环境、 布局窄带物联网、建设储能和能源管理系统以及使
用虚拟现实（VR）技术进行安全管控等。

在智能航运方面, 从全球范围看, 以北欧为代表 的多个国家, 均在积极推动智能航运研究。2016 年, 商船三井株式会社宣布成立智能航运办公室, 旨在 努力实现其新技术开发理念之一的 “用于更安全 船舶运行的先进支持技术”，通过基于信息通信技 术应用，从而成为客户可靠的物流业务合作伙伴。 2017 年, 瓦锡兰集团收购英国 Guidance Marine 公 司，利用 Guidance Marine 公司的核心竞争力（包 括高精度控制应用的位置测量传感器和系统开发), 对瓦锡兰集团在雷达技术、导航和动态定位领域的 活动形成互补, 加速将航运引入一个新的效率时代。 
2018 年, 韩国三星重工集团宣布选择亚马逊网络服 务系统 (AWS) 作为其首选的云计算服务供应商, 以支持韩国三星重工集团发展自主航运、向数字化 转型, 在智能航运中取得优势。

\section{（二）国内智能船舶技术的发展现状}

在智能船舶装备方面, 2017 年, 中国船舶集团 工业有限公司交付首艘智能船舶 “大智号”, “大智 号” 相较于常规船舶, 可向船东提供更为全面深入的 数据采集、分析挖掘和决策优化服务, 从而降低营运 成本, 减少关键系统和设备故障, 缩减设备维护成本, 使船舶更加安全、环保、经济和舒适 [4]。2018 年, 广东珠海万山无人船舶海上测试试验场正式启动建 设。该试验场计划建设成为亚洲首个无人船海上试验 场, 并将成为世界上面积最大的无人船海上测试场。

在智能设计方面, 2007 年, 上海申博信息系 统工程有限公司和上海船厂联合开发船舶制造三维 设计系统 SB3DS。2012 年, 南通中远海运川崎船 舶工程有限公司在数字化设计 (CAD) 系统的基础 上, 开发了数字化工艺设计 (CAPP) 和数字化制 造 (CAM) 系统, 进一步推动了产品生产设计协同 一体化的进程。

在智能制造方面, 2015 年, 南通中远海运川崎 船舶工程有限公司第 4 条机器人自动化生产线点火 投产, 该生产线自动化程度高, 机器人和焊接部材 均可灵活转换, 效率可提高 $40 \%$ 以上, 可保障全 天作业。2018 年, 武昌船舶重工集团有限公司推出 国内首条船舶工业智能无人生产线。据悉, 该生产 线年产量可达 3 万根, 采用激光视觉系统, 打通组 对焊接系统全流程, 将现有生产线产能提高 $15 \%$, 实现无人全自动化直管柔性制造。

在智能航运方面, 2014 年, 上海洋山深水港四 期码头正式开始建设, 该码头首创多元化堆场作业 交互模式，同时运用了电力驱动技术、第二代港口 船舶岸基供电、节能新光源、太阳能辅助供热等技 术, 是 “零排放” 的 “绿色码头”。2018 年, 中远 海运集装箱运输有限公司新版电子商务平台的网站 正式上线。新版网站从以往船东视角转向用户视角, 以 “客制化” 服务 (以满足客户需求为出发点的定 制化服务) 为出发点, 围绕用户的诸多痛点来对各 项功能和流程进行不断地优化, 为客户推出主动推 送的信息服务。

\section{（三）智能船舶技术发展现状分析}

1. 国外智能船舶技术发展循序渐进, 分阶段实施

从国外智能船舶技术发展路线来看, 先后经历 了信息集成阶段、信息互联互通阶段、信息分析处 理阶段及实船应用示范阶段。在信息集成阶段, 具 有代表性的是信息集成平台, 主要收集船体能源消 耗、航行环境、船载设备等方面的数据; 在互联互 通阶段, 主要集中于通信技术发展, 如有/无线船 舶综合管理网通信技术, 旨在建立船- 岸、船一船 之间的信息交互; 在信息分析处理阶段, 将互联网 技术、人工智能技术、数据分析技术运用在船舶的 数据处理分析上, 以此监测控制船舶运营状态; 而 实船试验及应用示范阶段, 则主要集中于成品智能 船舶的研发 $[5,6]$ 。

2. “辅助决策” “自主航行” 是智能船舶技术发 展的重点方向

辅助决策主要是指通过建立专家数据库系统, 为船舶设计、建造、营运以及拆解的船体结构安全、 故障诊断等提供决策建议, 利用传感器技术监测和 采集船体结构及设备的数据信息, 为船舶航行提供 决策依据。自主航行是指通过网络数据分析平台, 对船舶在营运过程中感知到的信息进行研究分析, 对船舶航线及航速进行辅助优化; 进一步通过建 立岸基中心, 船舶实现在开阔水域、狭窄水道及 复杂海况下的自主靠离泊、自主避碰, 即所谓的 自主航行。

3. “智能船厂”技术发展迅速, 逐渐形成 “三 步走” 的发展战略

近年来, 包括日韩在内的船企在推行 “智能船 厂”方面开展了大量的工作, 并在研究发展过程中 逐步形成“三步走”的发展战略。如韩国的“三步走” 战略: (1)实现信息管理系统集成, 制造过程全面自 动化、数字化和智能化, 基于物联网技术的全要素 实时监控与管理; (2)实施数字化虚拟智能船厂建 设; (3)迈向人与环境相协调的智能船厂。日本船企 则是瞄准先进信息技术, 推动大数据、物联网、虚 拟现实技术和产业发展深度融合：(1)作业过程可视 化与数据化; (2)推进 “智能造船集群”, 减少造船 各环节中的浪费; (3)引进智能装备优化建造流程。

4. 智能航运向无人运营时代迈进, 综合服务平 台助力智能航行发展

基于云存储和大数据分析技术, 以无人船为代 
表的智能航运变得不再遥不可及。通过对货物发出 及到达时间、最优航行线路等信息进行测算，无人 船根据实时天气、海况以及港口信息数据分析, 调 整航行计划, 实现最优航行路线 [7]。此外, 利用 物联网技术、船舶自动识别系统（AIS）定位技术， 加强对航运状态的动态监测与感知, 综合服务平 台能够实现跨部门和跨区域的信息资源共享、业 务协同处理和综合服务, 降低物流成本, 节能减 排, 形成畅通、高效、平安、绿色的现代化航运 体系。

\section{三、我国智能船舶技术的现状与差距}

在智能船舶装备方面, 当前我国船舶制造业 取得了一定的成绩，但在快速发展的同时，遇到 的问题和挑战也同时制约着我国造船业的发展。 智能船舶的到来, 为我国船舶工业加快实现转型 升级、抢占市场先机、提升核心竞争力提供了突 破口。近年来, 我国对智能船舶的研制步伐不断 加快。基于前期研究工作基础, 我国在智能船舶 发展上取得了一定成果。通过对国内外智能船舶 发展情况的研究可知, 智能船舶作为新兴发展方 向, 虽然我国在某些方面与国外研究还有差距, 但整体差距不大。

在智能设计方面, 我国船企在设计过程中已 应用三维建模, 但还远未实现全过程的三维设计, 同时设计与建造仍作为两个独立的系统分别运作， 未能形成协同操作，没有将设计成果直接应用于 建造。在设计建造的某些阶段应用了数字化, 但 未综合考虑从设计到建造的全过程, 数字化程度 还较低。

在智能制造方面, 整体而言, 我国当前仍处于 规划探索阶段。主要体现在: (1)船舶设计数字化技 术储备不足; (2)船舶制造装备与系统的自动化、智 能化水平低; (3)造船过程管控缺少有效的数据支 持; (4)数字化工艺设计能力严重不足, 其中包括三 维数字建模数据源不唯一、工艺信息不完整及缺乏 工艺数据库支撑 [8]。

在智能航运方面, 我国智能航运建设比欧美国 家相对落后, 无论是理念上还是技术上都尚未成熟, 信息化往往沿用传统、落后的管理信息系统开发理
论与方法，企业信息化系统各自为政。信息化与 航运企业管理业务匹配度不高, 不能很好地提供 服务; 航运企业智能化认识不深刻, 不能提出明 确的航运智能化需求, 缺乏科学的、可持续的智能 化规划 [9]。

\section{四、我国智能船舶技术发展保障措施与建议}

\section{（一）注重顶层设计, 制定阶段化的研发策略}

现阶段, 世界各国在其智能船舶的技术发展中 都制定了详细的研发策略, 并按时间节点分步推进 其发展计划和目标。此外, 主要智能船舶研发机构 十分注重技术研发与产品应用相结合的发展模式, 并推出了一系列智能船型。因此, 建议我国在推进 其智能船舶研发项目中，注重制定较为详尽的研发 策略, 按计划推进智能船舶有关技术发展; 同时加 强智能船舶设计推广和应用示范, 推进智能船舶产 业化发展。

\section{（二）借助行业外力量, 多方合作提升技术研发能力}

智能船舶技术涉及多个行业的先进技术, 国外 智能船舶研发机构在推进技术研发过程中, 纷纷采 取多方合作的方式来提升其智能船舶技术发展。值 得注意的是, 合作的对象不仅仅局限在船舶行业, 大量在数据信息处理、卫星通信、计算机技术领域 占据领先地位的研发机构或企业，成为国外造船业 争相合作的对象。因此, 建议我国造船业加强行业 间的相互合作，与相关领域占据技术优势的企业展 开合作, 推进智能船舶产学研合作力度, 推动智能 船舶技术综合发展。

\section{（三）加强互联互通，提升船舶综合服务保障能力}

船岸一体化是智能船舶技术发展的重要方向, 通过建立信息交互平台和岸基中心，实现船舶、岸 基中心、船东、造船企业之间的信息互联互通。同 时，船厂也将由单一的船舶制造向船舶全生命周期 方向转变, 以此在船舶运营中提供更好的服务。建 议我国在智能船舶研发过程中注重岸基中心的建 设, 建立覆盖全球的智能船舶及配套设备服务平台, 以适应智能船舶发展的新模式, 实现由单纯船舶制 造向综合服务的转变。 


\section{（四）加强多层次人才队伍建设，注重国际技术交 流合作}

以多种方式吸引智能船舶高层次人才，培养一 批领军人才和青年拔尖人才，加强智能船舶相关学 科专业体系和人才培养体系建设。大力开展国际技 术交流活动，采取科技合作、技术转移、技术并购、 资源共同开发与利用、参与国际标准制定等多种 方式, 快速提升我国智能船舶技术的发展水平与 创新能力。

\section{参考文献}

[1] 柳晨光, 初秀民, 谢朔, 等. 船舶智能化研究现状与展望 [J]. 船 舶工程, 2016, 38(3): 77-84.

Liu C G, Chu X M, Xie S, et al. Research status and prospect of ship intelligence [J]. Ship Engineering, 2016, 38(3): 77-84.

[2] 贺辞. CCS 《智能船舶规范》六大功能模块要求 [J]. 中国船检, 2016 (3): 84-85.

He C. CCS 《Rules for intelligent ships (2015)》 requirements for six functional modules [J]. China Ship Survey, 2016 (3): 84-85.

[3] 梁云芳, 谢俊元, 陈虎智, 等. 智能船舶的发展研究 [C]. 舟山: 纪 念《船舶力学》创刊二十周年学术会议, 2017.

Liang Y F, Xie J Y, Chen H Z, et al. Research on the development of intelligent ships [C]. Zhoushan: Proceedings of the Academic Conference Commemorating the 20th Anniversary of the Founding of Ship Mechanics, 2017.

[4] 曾晓光. 日本造船的智能化突围 [J]. 中国船检, 2018 (7): 36-37. Zeng X G. Intelligent breakthrough of Japanese shipbuilding [J]. China Ship Survey, 2018 (7): 36-37.

[5] 林赛宇, 钟蹈. 智能船舶与智能航保的关系探讨 [J]. 科技创新 导报, 2018 (25): 120-122.

Lin S Y, Zhong T. Discussion on the relationship between intelligent ship and intelligent aviation security [J]. Science and Technology Innovation Herald, 2018 (25): 120-122.

[6] 夏启兵, 王玉林, 陈蓉. 智能航运发展研究 [J]. 航海, 2018 (2): 43-46.

Xia Q B, Wang Y L, Chen R. Research on the development of intelligent shipping [J]. Navigation, 2018 (2): 43-46.

[7] 郑荣才, 杨功流, 李滋刚, 等. 综合船桥系统综述 [J]. 中国惯性 技术学报, 2009, 17(6): 661-665.

Zheng R C, Yang G L, Li Z G, et al. Overview of integrated bridge system [J]. Journal of Chinese Inertial Technology, 2009,17(6): 661-665.

[8] 杨敬堡, 林丞丰. 船用燃料电池模块系统设计研究 [J]. 中国水 运, 2017 (2): 46-47.

Yang J B, Lin C F. Study on the design of marine fuel cell module system [J]. China Water Transport, 2017 (2): 46-47.

[9] 张艳. 气泡船节能关键技术与应用前景 [J]. 中国水运(下半月), 2015, 15(2): 94-95.

Zhang Y. Key technologies and application prospects of energy saving for bubble ships [J]. China Water Transport (Second Half of the Month), 2015, 15(2): 94-95. 